Abou Dargham, S., Bou Hatoum, M., Tohme, M., and Hamzeh, F., (2019). "Implementation of Integrated Project Delivery in Lebanon: Overcoming the Challenges." In: Proc. 27th Annual Conference of the International. Group for Lean Construction (IGLC), Pasquire C. and Hamzeh F.R. (ed.), Dublin, Ireland, pp. 917-928. DOI: https://doi.org/10.24928/2019/0242. Available at: 〈www.iglc.net>.

\title{
IMPLEMENTATION OF INTEGRATED PROJECT DELIVERY IN LEBANON: OVERCOMING THE CHALLENGES
}

\author{
Sarah Abou Dargham¹, Makram Bou Hatoum², Mohammad Tohme ${ }^{3}$ and Farook \\ Hamzeh $^{4}$
}

\begin{abstract}
Integrated Project Delivery (IPD) approach is important to deliver value and reduce waste by integrating the stockholders early in a project. Despite its numerous advantages over the traditional delivery systems, IPD's applicability in the Middle East has not yet reached its potential. In Lebanon, the construction market is dominated by delivery practices such as design-bid-build or design-build. The aim of this paper is to examine the Lebanese construction industry experiences in project delivery methods and their attitudes towards shifting to Integrated Project Delivery. Research is conducted through surveys and interviews with industry professionals to investigate the performance of the traditional delivery approaches and the implementation of IPD in Lebanon. The data collected will be used to evaluate and critique the construction industry current project delivery practices, analyze the experts' awareness and attitudes toward IPD delivery method and identify the main barriers that prevents practitioners from implementing IPD.
\end{abstract}

\section{KEYWORDS}

Integrated Project Delivery, Contracts, Lean Construction, Traditional Delivery Approach, Lebanon, FIDIC.

\section{INTRODUCTION}

Integrated Project Delivery (IPD) has offered a great deal of improvement by maximizing value and reducing waste through the early collaboration of cross-functional teams to align goals and share risks and rewards through a relational contracting approach (Matthews \& Howell, 2005). In the contractual frame work, IPD agreements define new set of rules that limit liability and hierarchical management approach and enhance the flow of information

1 Graduate Research Assistant, Civil and Environmental Engineering Department, American University of Beirut, Lebanon, sra26@mail.aub.edu

2 Graduate Research Assistant, Civil and Environmental Engineering Department, American University of Beirut, Lebanon, mnb23@mail.aub.edu

3 Civil Engineering Graduate, Civil and Environmental Engineering Department, American University of Beirut, Lebanon, mht18@mail.aub.edu

4 Associate Professor, Civil and Environmental Engineering Dept., University of Alberta, Canada, hamzeh@ualberta.ca 
and creativity. Several professional organizations are striving to adopt the IPD approach, and some successful projects have demonstrated its huge potential in delivering projects with high quality and lower costs. However, its application in the Middle East is still marginal because of the required perquisites for its implementation (i.e. technological, legal, and cultural); thus, the number of projects adopting IPD remains relatively small (Hamzeh at al 2019; Korb et al., 2016). In Lebanon, it is yet to be adopted.

The construction industry in Lebanon and the Middle East (ME) is governed by traditional delivery approaches: design-bid-build, construction management (agency or atrisk), or design-build. These types of contractual delivery have historically resulted in an enormous amount of claims, high risks and late schedule and over budget projects. Some attempts have been made to avoid such conflicts such as post design constructability reviews, value engineering exercises, partnering and contractual efforts to shift the risk (Lichtig, 2006). However, these approaches merely solved the ongoing issues in construction delivery. The industry is in a crucial need for improvement which can be done by shifting to the integrated approach.

Since IPD remains a concept in Lebanon, few studies about its implementations have been conducted. This paper serves as an attempt to present the current state and practises in the Lebanese construction industry, to analyse the industry's attitudes and notion of the IPD method and to identify the main hurdles that may prevent its implementation.

\section{Integrated Project Delivery}

IPD is a new approach of delivering construction projects that aims to increase the value in the eyes of the customer, increase profit for all parties through mutual benefits, enhance communication, appropriate technology, and high performance (AIA, 2007). In other words, it is organizing the work and goals of all project teams under one unified goal.

\section{FUNDAMENTAL REQUIREMENTS FOR IMPLEMENTING IPD}

Contractual Requirements: IPD contracts are considered to be "relational" contracts because they consider the process and not only the end product (\& Gerber, 2011). AIA C195, AIA C191, ConsensusDocs 300, and IFOA are the most common IPD contracts. These contracts secure shared financial risks and rewards, and guarantee collaborative decision-making, liability and integrated design. Unlike the traditional contractual structure that aim at shifting risk from party to party, relational contracts align the commercial terms of participants (Thomsen et al., 2009).

Technological Requirements: A successful IPD process must adopt technologies that integrate information across all stakeholders such as Building Information Modelling (BIM). BIM is a 3D technology that provides integration in design, construction and management; it improves coordination in construction industry and enhances collaboration among teams (Eastman et al., 2011). On the other hand, Lean tools such as Last Planner System (LPS) Value Stream Mapping (VSM), A3 reports, etc. are considered complementary to the technological requirements and necessary for IPD implementation and often used as the IPD operational system (Mesa et al., 2019).

Cultural Requirements: Practices must secure collaboration, trust, and continuous improvement through trust-building activities and IPD training (Ghassemi \& Gerber, 2011). 
It is a part of lean philosophy making open communication an important requirement to deliver a successful IPD project.

Financial Requirements: In selecting compensation and incentive structures, fair distribution of shared savings and profit must be guaranteed (Rached et al., 2014). If selected properly, a concrete incentive structure will secure a professional project delivery.

\section{Current Delivery Methods in The Region}

Several types of traditional delivery approaches are used in the MENA Construction Industry, most notably is the design-bid-build (Hamzeh et al., 2019). And since the 1970s, companies in the Middle East use the Fédération Internationale des Ingénieurs-Conseils (FIDIC) family of contracts in their traditional project delivery approaches (Rached et al. 2014). The major systematic problems in traditional delivery methods include holding back ideas, limiting cooperation and innovation and promoting local optimization at the expense of the project. As for adopted contracts, they do not necessarily spur innovation at the project level since they limit coordination and collaboration (Wilkinson et al, 2012).

IPD research within the ME construction industry is very limited. Studies on the subject include an investigation of cultivating collaboration within ME industry by adopting IPD contracts done by Hamzeh et al (2019), an evaluation of the cultural acceptance of the ME industry to IPD practises done by Rachad at al. (2014) and finally a reflection on an IPD project done in ME presented by Korb et al. (2016).

\section{METHODOLOGY}

In order to fulfil the research purpose, a qualitative assessment was performed using survey questionnaire. The survey questions were developed based on similar studies and literature findings related to integrated project delivery systems. Then they were tested through mock interviews for further screening and fine-tuning. After identifying the survey respondents, the selected professionals were contacted to set interviews. An online version of the survey was drafted, yet it was filled and administered through face to face interviews. This method was utilized because it is not common in Lebanon to fill surveys online and usually the response rate with online surveys is very low. Also, because it yields more reliable results compared to online surveys, ensures that the new concepts of IPD are conveyed properly to the respondents and stimulates further input on the subject.

A cumulative of 23 interview hrs. were recorded with experts from different backgrounds and experience level, most of which are executives and seniors with a collective of 700+ years of experience in the Lebanese AEC industry. A total of 21 construction industry professionals completed the survey over a period of two months. Finally, the results were analysed using analytical tools provided by Excel to guide recommendations.

The originality of the study lies in addressing the IPD framework (standards, industry attitudes and perception, implementation etc.) from a Lebanese market perspective; a market not familiar with IPD systems. Therefore, the survey was tailored to collect facts and describe phenomena through 42 questions mixed between rate and open-ended questions. The survey outcomes were presented through descriptive statistic to present the 
and the market practises while the discussions aimed to display the respondent's perception and attitudes towards a foreign system based on their local experience.

The survey was divided into three sections. The first section was designed to gather general information about the respondent's profile, practices, and satisfaction with current project delivery practices. The second section reflects upon the participant's knowledge and value perception regarding IPD philosophies and tools. The third section investigates the respondent's opinion on factors that hinder IPD implementation in Lebanon and attitude towards adopting this delivery approach.

\section{SURVEY FINDINGS AND ANALYSIS}

The survey reported the findings of 21 construction industry practitioners with diverse professional background ranging from construction management consultants, architects and engineering consultants, owner representatives, general contractors, and subcontractors. $57 \%$ of the respondents were project managers and executives with more than 20 years of industry experience, $14 \%$ of respondents were seniors with 10 to 20 years of experience, $10 \%$ were mid-level practitioners with 5 to 10 years of experience and $19 \%$ of them were juniors with 5 or less years of experience. As for the contractual forms adopted by the practitioners, almost $38 \%$ reported to use a modified contract template based on FIDIC family of contracts (1987 and 1999 depending on the project), 10\% used FIDIC 1999 template only, 14\% use FIDIC 1987 template only and the remaining 38\% use their own company's template modified based on previous experiences. The replies also reflect that $90 \%$ of the participants were experienced with Design-Bid-Build (DBB) projects, 38\% of them had experience in Design-Build (DB) projects, 48\% had experience with Construction Management at risk (CM at risk), $20 \%$ were experienced with Staged DesignBid- Build and Multiple prime contractor and finally 5\% were involved in partnering projects.

\section{Project Delivery Practices in Lebanese Construction Industry}

According to the survey, the most common type of project delivery method practised in the Lebanese construction industry is design-bid-build. On the other hand, most of the contracts employed by industry are derived from FIDIC suits of contracts.

\section{Respondents Satisfaction with the Contracts Employed in the Market}

FIDIC is considered to pose certain limitations on different levels such as risk allocation, liability and insurance; it is also criticized for being biased towards the contractor more than the owner (Alves \& Shah, 2018; Hamzeh et al., 2019). Respondents were asked to rate their satisfaction with their employed contracts' ability to manage important factors using a Likert scale (1- Very dissatisfied to 5- Very Satisfied). The results are presented in Figure 1. 


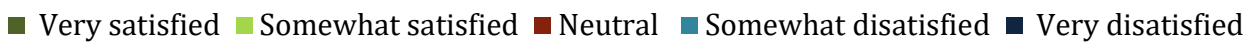
0\% 10\% 20\% 30\% 40\% 50\% 60\% 70\% 80\% 90\% 100\%

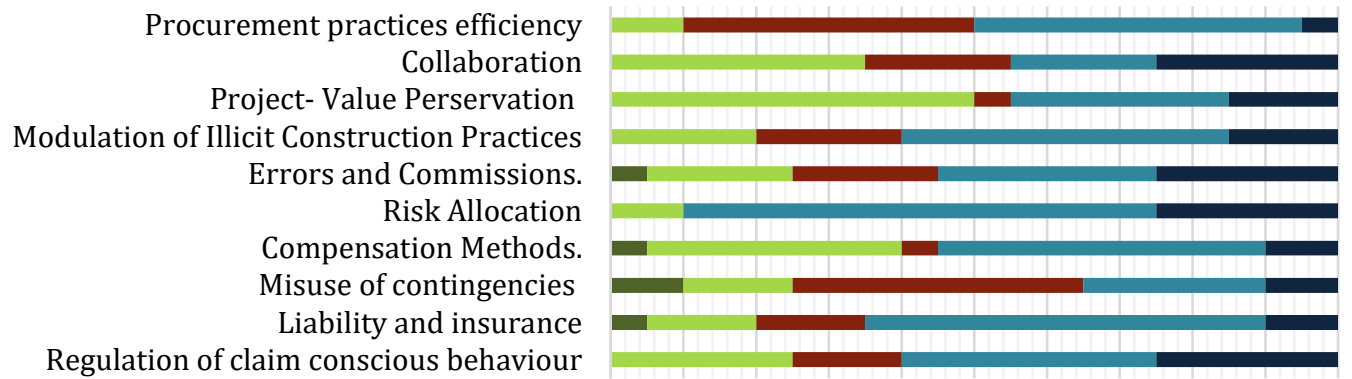

Figure 1: Satisfaction with the Contract Templates Employed in Lebanon.

The average of all means of each factor is 2.55 , indicating that practitioners are generally dissatisfied with the employed contracts abilities to manage the factors shown in Figure 1. More than $50 \%$ of the respondents were dissatisfied or extremely dissatisfied with factors related to risk allocation, liability and insurances, claim conscious behaviour, errors and commissions, illicit practises and compensation method.

\section{Respondents Satisfaction with the Project Performance}

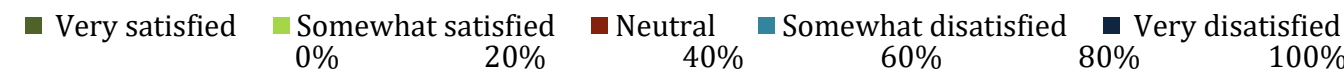

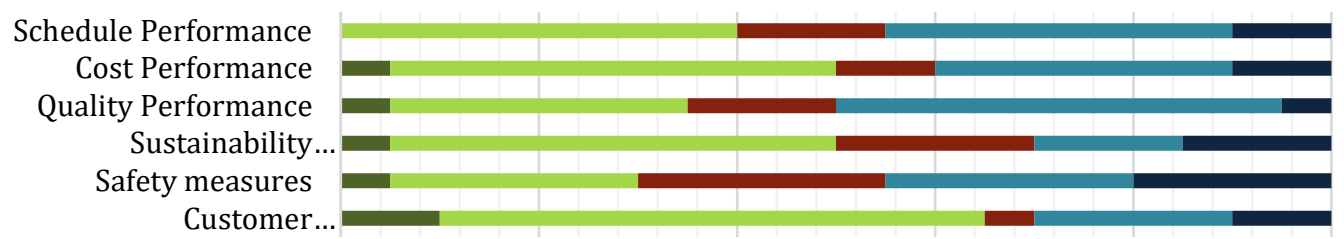

Figure 2: Respondents' Satisfaction with Project Performance.

Using the same Likert scale, participants were asked to rate their satisfaction with project performance based on a list of performance indicators introduced by El Asmar et al. (2015). The results in Figure 2 indicate for each KPI, nearly half the respondents were satisfied, and the other half were dissatisfied.

\begin{tabular}{ccc}
\hline Project Performance Criteria & Mean $(\boldsymbol{\mu})$ & Standard Deviation $(\boldsymbol{\alpha})$ \\
\hline Schedule Performance & 2.85 & 1.06 \\
Cost Performance & 3.05 & 1.16 \\
Quality Performance & 2.85 & 1.06 \\
Sustainability Performance & 3.1 & 1.18 \\
Safety measures & 2.7 & 1.19 \\
Customer Relationships & 3.35 & 1.19 \\
\hline
\end{tabular}

Table 1: Detailed Respondents' Satisfaction with Project Performance.

As shown in Table 1, respondents were mostly dissatisfied with their safety measures, quality and time performance. A major cause would be the dominating state of construction projects which are mostly behind schedule. The average of the displayed means is 2.98 
which indicates that respondents are neutral at best when it comes to their satisfaction with project performances.

\section{Reflection on Current Project Delivery Practices}

To further examine the market familiarity with the integrated project delivery practices, respondents were asked to state the frequency of occurrence of the following practices: participating in making and organizing a joint decision, facing communication issues between the various team members, adhering to the owner's specifications without alteration in design or construction, resolving project problems with different project entity outside the contractual obligations, signing a contract that contains comprehensive clauses which promote collaboration. The rating system used for these questions was a five point scale with (1) Never happened to (5) Always occurring. The results are shown in Figure 3.

A considerable number of respondents participated in a joint decision and participated to resolve construction problems outside contractual obligations on a regular basis. However, this phenomenon is limited to the construction phase of the project when most of the participants are on-board. Respondents also saw that help provided to other project entities outside the contractual obligations negatively affected the project and claims were referred to arbitration.

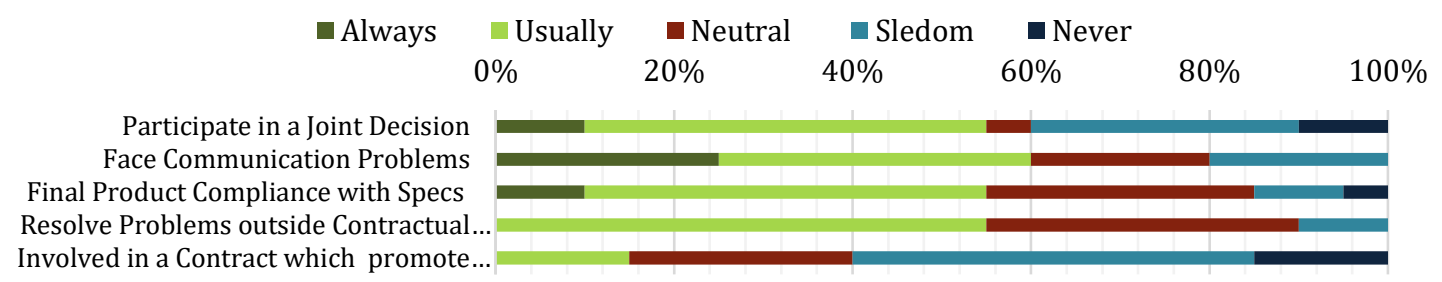

Figure 3: Respondent's Current Project Delivery Practices

\section{Collaboration Level in the Lebanese Construction Industry}

To examine whether the cultural prerequisites for integrated project delivery are present in the Lebanese construction projects, respondents were asked to reflect upon the collaboration level among project parties, to state examples of collaborative tools they used and to indicate factors that might hinder collaboration and information sharing based on their experiences.

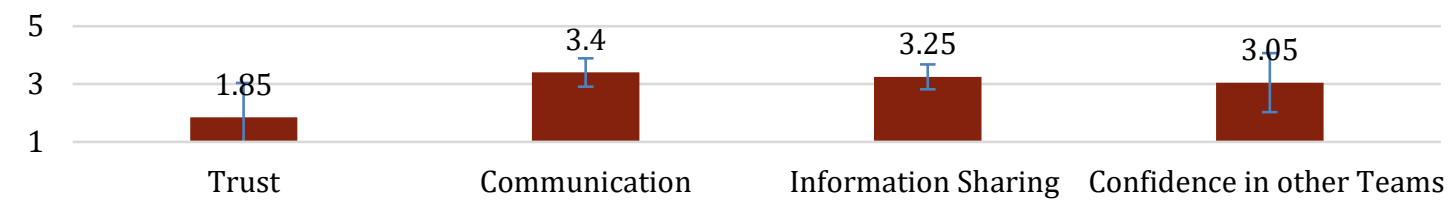

Figure 4: Level of Collaboration between Parties in a Project

Most of the participants agree that the parties involved in a construction project do not trust each other. This is evident in the responses to the question that address trust and goodwill intention among team members. The rating was done using a five-point scale with (1) indicating Trust is not present and (5) indicating Trust is always present. The results are shown in Figure 4. The computed average rating of trust was 1.85. According to the respondents, the lack of trust is the outcome of fraudulent practices and claim conscious 
behaviour among participants to gain extra profit. As a result, the contracts were modified to control these occurrences resulting in a stringent contract biased towards the construction entity and an unbalanced risk sharing between the three main construction teams (Architect/Engineer, Owner, and General Contractor).

The respondents were also asked to rate their confidence level in the experiences and capabilities of other team members using a scale of (5) Extremely confident to (1) Not Confident at all. Results show that most of them are either neutral or not very confident with a mean of 2.85. The distribution of the results however indicates that the percentage of the respondents who are confidant are somewhat similar to those who are not confidant (around 25\% each). These groups represent either the contractor's entity or the A/E entities. The latter voiced some concerns due to the presence of incompetent contractors on projects which results in degrading project performance in terms of quality. Consequently, the $\mathrm{A} / \mathrm{E}$ respondents tend to increase their insurance when confidence is not present, especially in DB projects when they operate as the owner's consultants which negatively affects the Trust attribute.

Moreover, participants were asked to rate the current construction practices in terms of communication and information sharing using a five-point scale with: (5) OpenCommunication present at all times and is highly encouraged; to (1) Communication is not present. A similar scale was applied for knowledge sharing. Reflecting upon the results related to these attributes in Figure 4 indicates that the majority of the respondents are somewhat satisfied with their collaborative practices suggesting room for improvement in the area. This is expected considering the trust and confidence related problems that is always present between parties. The interview discussions also indicate that the respondents consider basic coordination activities such as "weekly meeting during construction phase" as the main implemented collaborative tools which explains why this attribute had a higher mean value compared to other attributes

\section{IPD KNOWLEDGE AND AWARENESS LEVEL}

The survey aims to assess the participant's knowledge and awareness concerning IPD tools and philosophes. Respondents were asked to rate from 1 to 5 their level of knowledge when it comes to IPD delivery approach, Lean Construction tools (Last Planner System, Target Value Design), relational contracts (AIA, ConsusDocs, and IFOA), BIM and other integrated information systems. The results, summarized in the Figure 5, indicate that most of the respondents are not familiar with the IPD system and lean tools. Almost $30 \%$ of the respondents have been involved in a project where they used a shared information platform because the project complexities necessitate it. Less than $10 \%$ of the respondents are familiar with Lean construction tools.

On the other hand, most of the respondents reflected positively when asked whether they perceive certain project criteria such as early involvement of key team members, open communication and knowledge sharing among project teams, aligning interests of all project teams and contractual incentives: risk-reward sharing are requisites for project success. The results are displayed in Figure 6. These criteria were derived from basic IPD features provided by the American Institute of Architects (AIA) guidelines. The bar graph 
indicates that more than $80 \%$ of the participants agree that risk-reward sharing, and interest alignment are necessary for project success.

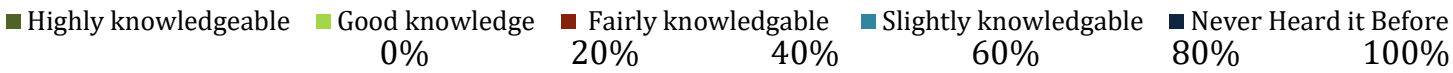

IPD delivery Approach IPD Contracts Templates Lean Construction Tools BIM Plateforms

Figure 5: Level of Knowledge Regarding IPD Tools

Based on the open-ended questions, most of the participants valued collaboration and working towards common project goals. And they seem to have tangible evidence based on their experience with projects where they collaborated with other parties.

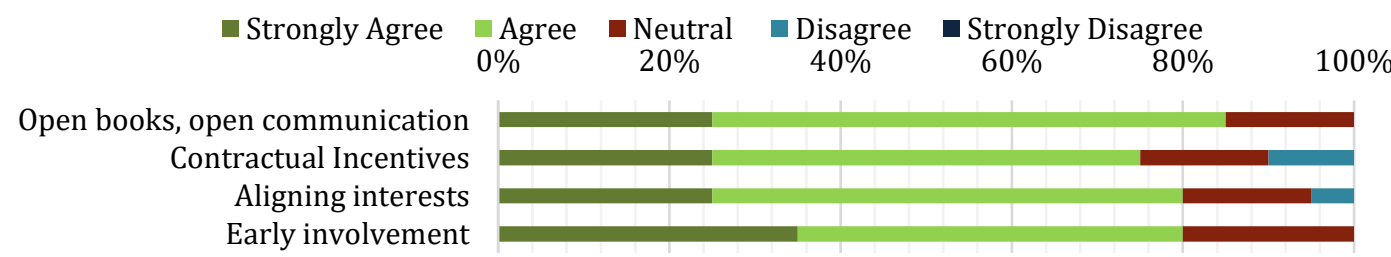

Figure 6: Respondent Viewpoint on Successful Project Criteria

\section{BARRIERS AgAINST IMPLEMENTING IPD IN LEBANON}

To assess IPD implementation barriers, questions in the survey were categorized based on the four IPD barriers: Legal, Cultural, Technological, and Financial identified by Kent \& Gerber et al. (2010). These barriers were adopted because they provide a holistic and sufficient representation of the all the identified barriers relating to IPD. Problems related to IPD implementation was identified by respondents based on their experience as follows:

Legal Barriers: Based on the respondent's feedback, most stated the government laws of biding and the current procurement practices as the main legal barrier. In the public sector, the lowest-bidder selection process is mandated by the government instead of value driven selection process. In the private sector, the owner has the complete freedom to decide on the bidder. This freedom promoted the unethical negotiation techniques whereby the owner negotiates with each contractor or design firm on specific prices to reduce the total bidding cost. As a result, incompetent teams are chosen and low-quality projects are generated. Many respondents expressed this concern and voiced that they have to deal with unskilled team members. Moreover, for large scale projects $\left(>50,000 \mathrm{~m}^{2}\right)$ the Lebanese Syndicate of Engineers mandate the contractor and designer to be from different entities. Another legal issue raised by one of the participants when dealing with the public sector is that the Council for Development and Reconstruction-CDR, the largest public owner in Lebanon, harbour their own contracts and are bound to use the FIDIC contracts when the project is funded by the World Bank. Moreover, the wide knowledge and usage of the FIDIC book gives it advantage over any other contract type. According to the respondents, owner entities usually prefer to use the 1987 FIDIC and the new impartial FEDIC 1999 remains not widely accepted among practitioners. This lag in contractual updates serves as another big barrier to adopting relational contracts. 
Cultural and Behavioural Barriers: As previously discussed, the Lebanese construction industry still lacks the collaborative attitudes. Projects lack the incentives for collaboration this can be attributed to local optimization practises, self-preservation attitude and corruption within the industry. The owner always tries to shoulder all the risks on the contractor through a well-structured contract which in turn leads to adversarial relationships between the different construction entities. When asked about participating in a relational contract one respondent replied: "If I want to be part of a team that shares risks then why am I paying them". Most respondents also argued that the Lebanese construction market is full of "immoral" and "self-centred" industry practices which may lead to problems in collaborative and risk sharing. On the other hand, others argued that IPD comprise set of principles that can be practised along with other delivery approaches such as collaboration.

Technological Barriers: Participants were well aware of the industry's deficiency from the technological perspective given the lack of knowledge in lean principles and IPD tools as shown previously. The survey indicated that only $30 \%$ of participants have previous experience with BIM platforms and their experiences is limited to one or two projects where the owner has mandated the use of a shared information platform. Most of the respondents related these barriers to the absence of capable contractors and financial incentives associated with the technological upgrade. However, they were aware that future market demand will require technological upgrades since more than $65 \%$ stated that they are willing to invest in technological upgrades opposed to $20 \%$ who are willing to invest in Lean tools. The lack of value perception of Lean tools as opposed to BIM platforms can be associated with the heavy BIM marketing and owners demands.

Financial Barriers: According to the respondents, the absence of a financially capable owner who has access to abundant resources of money to invest in and adopt a new delivery system was the main financial barrier. The absence of proper case-studies or evidence for the return on investment of adopting new delivery systems and the lack of knowledge about IPD contracts among owners and developers serve as the main reason behind the respondent's opinion. IPD is still considered a "risky business" in the Lebanese context.

\section{Lebanese Market Attitudes towards IPD Adoption}

The participants were asked whether they foresee the adoption of IPD by the Lebanese market in the future, and, if given the opportunity, they are willing to participate in an IPD project. The results are demonstrated in Figure 7.

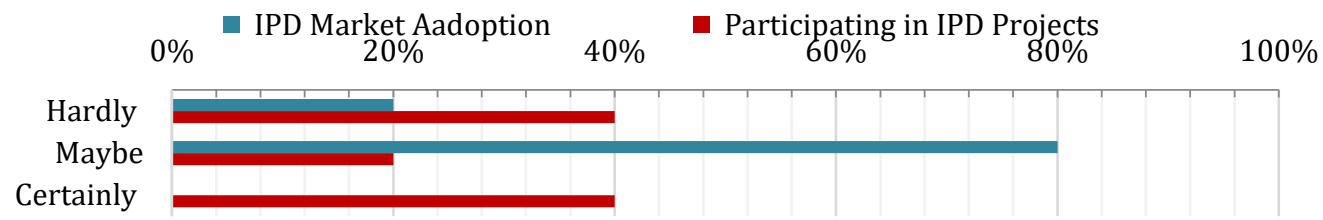

Figure 6: Lebanese Construction Industry Attitudes towards Adopting IPD.

Most of the respondents saw that the Lebanese market may eventually adopt IPD system. As for participating in an IPD project, some expressed willingness while others did not. This indicates that the practitioners are well aware of the inefficiencies of current 
project delivery practises but not yet confident about the IPD's ability to blend in the Lebanese environment. Comparing the results of Figure 7 with that of Figure 1 indicates that $100 \%$ of the respondents who scored strongly and somewhat dissatisfied with the contracts foresee that Lebanon might adopt IPD. However, $25 \%$ of respondents who were satisfied and $33 \%$ who were neutral with the employed contracts foresee it's hard to implement IPD in Lebanon. This indicates that most of the Lebanese AEC firms have experienced the incapabilities of the traditional contracts to serve the growing demand and challenges of the industry and foresee the need for a change, yet they are not sure whether IPD might be the best replacement to the current delivery practises. And the fact that none of the respondents were certain or positive of the market adoption of IPD system can be attributed to the previously identified barriers as participants acknowledge the local industry shortcomings in terms of the technology, financial incentives, cultural inertia to change, illegal practices and self-preservation.

Also, linking the results of Figure 7 to those of Figure 2 shows that $100 \%$ of the respondents who scored strongly satisfied with project performance scored maybe in recommending IPD to their firm. As for those who scored satisfied with project performance their distribution among hardly, maybe and certainly was as follows 9, 64 and $27 \%$. Respondents that scored neutral with project performance were distributed equally among hardly, maybe and certainly (33\% each). And dissatisfied respondents were distributed between maybe and certainly as follows 80 and $20 \%$ respectively. In general, it can be deduced that dissatisfied firms clearly sees the benefits of being involved in an IPD project as none of the respondents considered the option Hardly. As for the neutral firms, it is alarming to realize that they are unsure whether or not a change is needed.

\section{CONCLUSIONS AND RECOMMENDATIONS}

The survey and interviews conducted shed light on the actual state of the project delivery methods in the Lebanese construction industry and voice the concerns of the practitioners concerning current practices that might act as barriers against the implementation of IPD. Although very few firms started implementing lean construction, the majority of the practitioners are either unknowledgeable or have some superficial knowledge regarding IPD systems. The findings of this study indicate that a successful IPD project in Lebanon needs to harbour trust, align stakeholder goals, and show willingness to invest in basic IPD tools. The study also reflects that some firms, though prefer the concepts of IPD standards over other traditional delivery practises, are sceptical to its applicability; this is due to an industry plagued with corrupt construction practices. Thus, a cultural change is imperative to the implementation of successful IPD projects in Lebanon.

Finally, the IPD method should be marketed within the industry. Construction management and contractual consultants who are experts in the field of IPD or Lean Construction should play a vital role in marketing this delivery method along with multiparty contracts within project management firms. Their responsibility would include educating the owners regarding IPD principles, tools and practices and emphasizing the value associated with such delivery approaches, especially at the level of financial gains. 


\section{REFERENCES}

AIA National and AIA California Council (2007), "Integrated project delivery: a guide", retrieved from http://info.aia.org/SiteObjects/files/IPD_Guide_2007.pdf

Alves, T.D.C. and Shah, N. (2018), "Analysis of construction contracts: searching for collaboration", In Constr. Research Congress, 148-157.

Eastman, C., Teicholz, P., Sacks, R., \& Liston, K. (2011). "BIM handbook: A guide to building information modeling for owners, managers, designers, engineers and contractors." New York: John Wiley \& Sons.

El Asmar, M., Hanna, A. S., \& Loh, W. Y. (2015). "Evaluating integrated project delivery using the project quarterback rating." J. Constr. Eng. Manage., 142(1), 04015046.

Ghassemi, R. and Becerik-Gerber, B. (2011). "Transitioning to Integrated Project Delivery: Potential Barriers and Lessons Learned." Lean Constr. J., 32-52.

Hamzeh, F., Rached, F., Hraoui, Y., Karam, A. J., Malaeb, Z., El Asmar, M., \& Abbas, Y. (2019). "Integrated project delivery as an enabler for collaboration: a Middle East perspective." Built Environment Project and Asset Manage. retrieved from https://doi.org/10.1108/BEPAM-05-2018-0084

Kent, D. C., \& Becerik-Gerber, B. (2010). "Understanding construction industry experience and attitudes toward integrated project delivery." J. Constr. Eng. Manage., 136(8), 815-825.

Korb, S., Haronian, E., Sacks, R., Judez, P. and Shaked, O. (2016), "Overcoming 'but we're different': an IPD implementation in the Middle East", Proceedings 24th Annual Conference of the International, Group for Lean Construction, Boston, MA, pp. 3-12.

Lichtig, A. William (2006). Quo, Status. "The Integrated Agreement for Lean Project Delivery.". Constr. Law., 26(3), 25.

Matthews, O., \& Howell, G. A. (2005). "Integrated project delivery an example of relational contracting." Lean Constr. J., 2(1), 46-61.

Mesa, H. A., Molenaar, K. R., \& Alarcón, L. F. (2019). Comparative analysis between integrated project delivery and lean project delivery. International Journal of Project Management, 37(3), 395-409.

Post, N. M. (2007). "Sutter health unlocks the door to a new process." ENR, retrieved from http://www.enr.ecnext.com/coms2/article febiar071121a-1

Rached, F., Hraoui, Y., Karam, A., \& Hamzeh, F. (2014). "Implementation of IPD in the Middle East and its challenges." Proc. 22nd Ann. Conf. of the Int'l. Group for Lean Construction, Oslo, Norway, 293-304.

Thomsen, C., Darrington, J.,Dunne,D.,and Lichtig,W. (2009). "Managing integrated project delivery." Constr. Management Association of America, McLean, VA, 105.

Wilkinson, P. (2012). "FIDIC - behind the times when it comes to collaboration?". Retrieved from http://www.archdaily.com/153953/integrated-project-deliverymethodology. 
Abou Dargham, S., Bou Hatoum, M., Tohme, M., and Hamzeh, F. 